\title{
The Logic of Democracy and Education
}

\author{
James Scott Johnston \\ Department of Philosophy, Memorial University of Newfoundland, St. John's, NL A1B-3X8, Canada; \\ sjohnston12@mun.ca
}

Academic Editors: Paul Standish and SunInn Yun

Received: 25 October 2016; Accepted: 14 March 2017; Published: 23 March 2017

\begin{abstract}
To the best of my knowledge; no one has ever exploited the relationship between Democracy and Education and Dewey's logical theory as presented in these other works. Doing so not only lends textual evidence to the important relationship between Dewey's logical theory and Democracy and Education; it reinforces Dewey's claim that Democracy and Education best represents his philosophy in general. Democracy and Education evinces arguments regarding logical theory that Dewey hadn't yet made in his published works on logical theory. These arguments concern the role and scope of scientific method in the context of the practice of teaching and the social psychology of learning. Attention to scientific method and to the habits and dispositions of the student-as-learner will be my focus. I argue that these arguments find their way into Dewey's later logical theory; represented in Logic: the Theory of Inquiry (1938) under the rubrics of 'the existential matrix of inquiry' and 'social inquiry.' In particular; the accounts of habit; adaptation; and interaction in Chapter 2 of Dewey's Logic; together with the account of social problems and their resolution in a genuine determination as discussed in Chapter 24; are indebted to Chapters 11-14 of Democracy and Education. And for this reason alone; Democracy and Education should be considered among the most important of Dewey's influences regarding the development of his logical theory.
\end{abstract}

Keywords: Dewey; logic; Democracy and Education; habit; continuity; inquiry

\section{Introduction}

Given the 100th anniversary of the publication of Democracy and Education (MW 9, 1916/1980 [1]) we would do well to reflect proudly on its revered place in worldwide educational theory and practice. This should extend to Dewey's inimitable estimation of the book. It is commonplace for Dewey scholars and educators alike to repeat Dewey's claim that for many years, Democracy and Education represented best the articulation of his philosophy in general (LW 5, 1930/1985 [2] (p. 156)). One of the ways in which Democracy and Education was valuable to Dewey beyond a coherent statement of his philosophy concerns his logical theory. Dewey's logical theory, represented in turn through his books Studies in Logical Theory (MW 2, 1903/1976 [3]), How We Think (MW 6, 1910/1985 [4]) and later compilations are also given attention in Democracy and Education, especially Chapters 11-14.

In 1916, Dewey published Essays in Experimental Logic [5] (certain essays of which can be found in MW 8, 1915/1985 [6]; MW 10, 1916/1985 [7]). Composed of his earlier Studies in Logical Theory, Essays added several published papers on aspects of pragmatism and method, as well as a new introduction and an extended essay published the year earlier as "the Logic of Judgments of Practice." Essays was to be Dewey's last comprehensive statement on logical theory until the publication of his magnum opus, Logic: the Theory of Inquiry, in 1938 (LW 12, 1938/1986 [8]). In the intervening 22 years, Dewey would publish major treatises on ethics, human nature, (naturalistic) metaphysics, a critique of rationalism, and social and political philosophy. He would also publish a major treatise on the philosophy of education, and do so in 1916-the very same year as Essays. However, on logical theory, he would remain relatively silent. Dewey would write papers on various topics of logical 
theory. He would present lectures on logical theory (in 1915-1916 and again, in 1927-1928), but not a book-length manuscript.

There is, however, development of Dewey's ideas from the standpoint of Essays to what would come to fruition as the 1938 Logic. This development can be traced in various writings as well as lectures Dewey gave in the intervening years. It stands to reason that Dewey's advancements in metaphysics (especially Experience and Nature (LW 1, 1925/1981 [9]) had a positive effect on his logical theory. It is also undeniable that Dewey's discovery or 're-discovery' of Peirce in the 1930s strengthened his account of continuity in the 1938 Logic. For Dewey in fact had two discoveries of Peirce: the first circa 1916, the second in the early-to-mid 1930s. The latter or 're-discovery' concerned the publication of Peirce's collected papers by Paul Weiss and Charles Hartshorne, of which Dewey reviewed two volumes. Moreover, though Bentley's correspondence with Dewey began only a few short years prior to the publication of the Logic (1932), it is a given that his correspondence with Bentley helped Dewey move the project into its final form. Bentley was helpful in Dewey's overall consolidation of aspects relating to the central focus of his book: the problem of the relationship of logic and logical theory to its subject matter (e.g., Ratner, in Ratner and Altman, 1964 [10] (p. 43)). He also helped Dewey in the discussion of language in Chapter 3. It is less obvious, however, that other aspects of Dewey's overall philosophy were germane to the project. One of these aspects, as I will now discuss, is his philosophy of education and particularly, his statements on method.

What, in terms of method, did Dewey draw from Democracy and Education that would find its way into his completed Logic? Dewey gives us an account of the learner in Democracy and Education: an account that is present in School and Society (MW 1, 1899/1976 [11]) and related articles Dewey penned in the years leading up to Democracy and Education. However, it is not as fleshed out as it is in Democracy and Education and it is not present in his earlier Studies (it is also found in the corresponding Existential Matrix of Inquiry-Cultural of the 1938 Logic. However, the analysis of this will have to wait for another time.) This account is first broached in How We Think. However, it is remoulded in Democracy and Education to serve an account of 'general method.' It is then combined with an account of habit-formation on the part of the learner: a formation that leads to certain positive dispositions for the learner. This account in Democracy and Education is situated in the Logic. It is found in Dewey's discussion of the Existential Matrix of Inquiry-Biological (Chapter 2), and chapters on Scientific Method and Scientific Subject-Matter (Chapter 23) and Social Inquiry (Chapter 24). I propose to undertake an examination of just what in Democracy and Education is novel for Dewey's burgeoning logical theory. I will examine Dewey's claims for habit-formation and dispositions as he constructs them in Democracy and Education and show how these resurface in his 1938 Logic. In Section 1 I examine the development in Dewey's account of method from How We Think to Democracy and Education and turn to the account of habit-formation and dispositions in the latter. I claim there are (at least) two contributions Dewey makes in Democracy and Education that add to his ongoing account of continuity. First, thinking not only bridges doing (acting) in the present and doing in the future, it is itself an aspect of experience (Dewey will say 'transaction') that has its beginning and endings, its traits and qualities, and its openness and closure. Second, thinking (habit) is the means for connecting events: thinking is the means of continuity and not only in the refined sense of noting temporal succession (e.g., causality) but at a deeper ontological level, the interconnection of qualitative events. In Section 2 I turn to Dewey's account of the matrices of inquiry. In Section 3 I examine Dewey's chapter in Logic: the Theory of Inquiry on Scientific Method and Scientific Subject Matter, and in Section 4 I examine Dewey's chapter on Social Inquiry and discuss how some of the arguments therein rely on earlier claims made in Democracy and Education.

\section{From How We Think to Democracy and Education: The Establishment of Continuity}

By 1910, Dewey had offered a stage theory of inquiry that was open-ended and recursive, a model of inquiry sufficiently flexible to forgo stepwise, linear progression and allow for entrance and exit at any one of the stages. Though the theory was again presented (in altered form) in 1932, it did not 
find its way into the Essays in Experimental Logic of 1916. The beginnings and endings of inquiry were present in Essays: the qualitative indeterminacy or lack of a situation sufficient to occasion an inquiry, together with the re-establishment of (qualitative) wholeness. However, the 'guts' - the accounts of inferences, of judging - were not present in the form Dewey had set it down in How We Think. In the most important of the Essays, "Logic of Judgments of Practice" (MW 8, 1915/1985 [6]), Dewey stressed the process of making judgments of value, though, as we have seen this had first been broached the previous year in Democracy and Education. Valuing takes place along a continuum in which a "change of mode of behaviour from direct acceptance and welcoming to doubting and looking into-acts which involve postponement of direct ... action which imply a future act having a different meaning from that now occurring ..." occurs" (MW 8, 1915/1985 [6] (p. 30)). When we pass judgment we do so in regards to the connections with other acts. To make a judgment of value is to make a judgment of what to do and this is the "future termination of an incomplete and in so far indeterminate situation" (MW 8, 1915/1985 [6] (p. 30)). The judgment, in other words, takes place in an existential context and involves not objects, but situations; events (MW 8, 1915/1985 [6] (p. 31)).

Now Dewey discusses the indeterminate situation and its role in initiating inquiry at length in How We Think (MW 6, 1910-1911/1985 [4] (pp. 262-263)). However, what he does not stress is the existential continuity of events. A complete act of thought has its beginning and ending: it is a qualitative whole. However, this seems to suggest that one situation or event is cut off from another. In "the Logic of Judgments of Practice," Dewey suggests otherwise. For in the latter work, values are traits. Traits are not of objects but situations; events. Traits of situations are directly related to the judgment of a situation such that a value arises in consideration of the existential quality of that situation (MW 8, 1915/1985 [6] (p. 32)). Values are not ab extra: they arise as considerations of an event. Inquiring into and considering a situation is valuing. While values certainly seem to be individuals in that they accompany judgments of situations, they in fact are linkages in a series of meaningful interactions. Dewey makes this point abundantly clear in Democracy and Education: when we think, we make connections between doing and the consequences that result from doing. "Thinking, in other words, is the intentional endeavor to discover specific connections between something which we do and the consequences which result, so that the two become continuous" (MW 9, 1916/1980 [1] (p. 157)).

Dewey follows in outline the complete act of thought as discussed in How We Think. However, in Democracy and Education, he stresses an aspect of thinking merely glossed in the latter work: thinking itself is an experience (MW 9, 1916/1980 [1] (p. 174)) Dewey broaches the topic of thinking as experience in his claim that every mind at every stage of development has its own logic, and that the union of the psychological and logical is, properly speaking, a continuum. However, the focus here is on the role of mind in natural growth and development, not experience per se. Furthermore, experience is "a single continuous interaction of a great diversity (literally countless in number) of energies" (MW 9, 1916/1980 [1] (p. 174)). And what links these energies is that "every conception and statement shall be of such a kind as to follow from others and lead to others" (MW 9, 1916/1980 [1] (p. 174)). Energies here denote activities: what we do when we have and undergo an experience. They also invoke the biological basis of the human as organism. Energies are activities of the organism as it responds to its environment. Energies includes modifications the organism makes in regards its environment, including modifications Dewey calls habit, and what we do when we undergo an experience in which thinking is predominant is connect. We connect conceptions to propositions and propositions to existential phenomena; we connect values to values, ideas to ideas, and meanings to meanings. We form an unbroken chain of continuous doing and undergoing. Thus, while at one level, having an experience is a finished affair with a beginning and ending, and the sense of accomplishment a felt because qualitative whole, at another it is a moment, a link, a node in a series of experiences made possible in thought.

Dewey applies this insight to the question of the subject matter of education. As Dewey insists, subject matter is not to be divorced from the learner (MW 9, 1916/1980 [1] (pp. 192-193)). The logical corollary to this is form, including the formal aspects of inquiry (principles, standards, ideas, concepts), 
and matter (as the existential-phenomenal material inquiry works with) are separated only for functional purposes, and do not come existentially distinct. This was a central insight of Studies in Logical Theory (1903/1976) and it will factor heavily in his 1938 Logic. Indeed, we might even say that this is Dewey's preoccupation in the Logic. Thus, Dewey can talk of the development of subject matter in the learner as subject matter is material already shaped by knowledge through acquaintance. This is know-how, and while this is not coeval with knowledge formed through inquiry into existing conditions, it is the basis for subsequent inquiry (MW 9, 1916/1980 [1] (p. 192)). This is also the basis for social knowledge, for we learn new habits through interacting not only with subject matters but with subject matters through others. What Dewey calls "Modes of purposeful doing," already invites and invokes intercommunication (MW 9, 1916/1980 [1] (p. 193)). A central goal of education is to connect refined knowledge ("information") to the learner's existing knowledge by acquaintance (MW 9, 1916/1980 [1] (p. 194)).

The series of habits developed and practiced implies an ongoing construction and reconstruction of actions and reactions. To this Dewey assigns the term, "consistency", and equates it with "totality" and "continuity" (MW 9, 1916/1980 [1] (p. 335)). Habits, as with all else regarding thought, grow. They are adapted and reconstructed as the situation demands (MW 9, 1916/1980 [1] (p. 335)). They of course rely upon the totality of the series of dispositions and actions that constitutes the habit at a specific point in time, but they also include and gesture to their transformation, their change. The connection between past iterations of habit and the present (and future) instance is continuity. When we assign causality to events, we mark them as temporally related. We draw the (temporal) inference. However, there is a deeper, more metaphysical and underlying continuity at work in thinking: this is the connection of present habit to past habit, together with all the traits and characteristics of habit (tempers and attitudes, judgments, dispositions, actions, and of course values) in a pattern or series. It is the business of reflecting to make these connections and this, too, is an aspect (the refined aspect) of experience (LW 1, 1925/1981 [9] (p. 15)).

\section{Continuity in the Logic: Biological}

As we see, thinking bridges acting and doing, present and future. It is itself an aspect of experience that has its beginnings and endings, openings and closings. Thinking is habit, and is the means for relating events to one another, both in the senses of temporal succession (causality) and connection of events. Of course, Dewey will go on to say much more about continuity (as "constant relations") in Experience and Nature (LW 1, 1925/1981 [9] (p. 308)). However, I am interested in the implications for logical theory. Continuity is a pervasive theme in Dewey's 1938 Logic. Indeed, it is probably not too much to say it is the predominant theme, given Dewey's isolation of this specific trait in the preface, together with his almost constant attention to it in the text. In the follow sections will focus on two areas regarding continuity I think are directly influenced by Dewey's claims in Democracy and Education: these areas concern the Existential Matrix of Inquiry: Biological, and Scientific Method and Scientific Subject-Matter, together with Social Inquiry.

Dewey's understanding of continuity in regards the existential matrices of inquiry is naturalistic and consists in development of activities and forms from lower to higher (LW 12, 1938/1986 [8] (p. 30)). Dewey rejects accounts of continuity that imply or invoke Reason or a priori intuitions in inquiry (LW 12, 1938/1986 [8] (p. 31)). The basis for any account of continuity lies in the transaction of the organism with its environment. This transaction Dewey in other contexts gives the name "experience", though here he stresses the more Aristotelian-sounding term, "energies" to denote the active nature of this (e.g., LW 12, 1938/1986 [8] (p. 32)). There is an integration of organism and environment; an integration that, on the part of the organism, results in growth and development when the conditions for energy accumulation emerge (LW 12, 1938/1986 [8] (p. 33)). Dewey calls this accumulation of energies, "surplus balance" (LW 12, 1938/1986 [8] (p. 33)).

On the part of the organism, there are continuing shifts in the balance between forces attempting to maintain equilibrium and forces attempting disequilibrium. In responding to its environment 
(including its internal environment), an organism is in a nearly constant state of tension between equilibrium and disequilibrium (LW 12, 1938/1986, [8] (pp. 33-34)). Dewey calls the state of disequilibrium "need," and the state of (re) equilibrium, "satisfaction" (LW 12, 1938/1986 [8] (p. 34)). Repeated satisfactions constitute growth on the part of the organism: a growth which Dewey refers to in this context as "adaptation:" adaptations in turn concern "the more extensive development" Dewey calls "evolution" (LW 12, 1938/1986 [8] (p. 35)). The activities generated on the part of the organism are themselves developmental, having characteristics of lower, intermediate, and higher (LW 12, 1938/1986 [8] (p. 36)) (Dewey doubtless has Myrtle McGraw in mind, here. McGraw was an experimental psychologist and neurologist studying the reflex patterns of infants and Dewey drew on her research. For more on this, see [12] (pp. 232-233)). And while behaviourally, it is acceptable to call these activities 'stimulus-response mechanisms,' Dewey reminds that, for the total organism, reflexivity of behaviour occurs not in dyadic manner, but as part of a reflex-circuit (LW 12, 1938/1986 [8] (p. 37)). The upshot of this is behaviour that is serial, sequential, not scattershot or a mere succession of individual behavioural units (LW 12, 1938/1986 [8] (p. 37)).

In a reflex-circuit, the "open phase" is the point of disequilibrium. The "closing phase" is the point of (re)equilibrium. In terms of behaviour, the (re)equilibrium represents a change of the environment by the organism. This change, Dewey calls a "modification." And a modification, for Dewey, is a "habit" (LW 12, 1938/1986 [8] (p. 38)). Habits are the bases of all learning (LW 12, 1938/1986 [8] (p. 40)). Habits form out of the settlement of a previously unsettled event or situation: an event that is constituted of the transaction between organism and environment. Dewey calls this re-settling "integration," and this in turns constitutes a "pattern", both spatial and temporal (LW 12, 1938/1986 [8] (p. 40)). The temporality of the pattern consists in its serial or sequential nature. The form and matter of habits are these patterns, and once habituated, these patterns are susceptible of recollection (LW 12, 1938/1986 [8] (p. 41)). Through recollection, ends and means of behaviours can be established. Of course, this is inquiry as Dewey understands it, and all of this leads to his larger point: inquiry is set of "serially connected processes or operations" by which closure of unsettled events or situations (disequilibrium) takes place (LW 12, 1938/1986 [8] (p. 41)).

It is not from How We Think or even Studies in Logical Theory that Dewey draws in his explication of the role of habit as the (biological) basis of inquiry: it is from Democracy and Education. (Dewey would of course go on to discuss habit formation in matters of human conduct much more fully in Human Nature and Conduct. However, this was not until 1922-fully 6 years after his accounting in Democracy and Education.) There, Dewey discusses the serial and sequential nature of habit-patterns as "consistency", or "totality" (MW 9, 1916/1980 [1] (p. 335)). However, these are coeval with continuity as far as Dewey is concerned. As far as the sorts of experiences that are conducive to genuine learning are concerned, it can only be those that usher in a transformation in the organism-in the context of Democracy and Education, the learner-and this because the learner has successfully adapted herself through adapting her environment in the resolution of the problem at hand. Adaptation in regards one's environment is adjustment in the context of Democracy and Education. These invoke and imply continuous-because-serial sets of habit-patterns that, when forged in an inquiry, establish the conditions for the solution of an otherwise indeterminate event or situation and bring resolution to the event in the guise of a satisfactory whole.

\section{Continuity in the Logic: Scientific Method and Scientific Subject Matter}

That the content of scientific investigation differs from our direct perceptions of it is a premise Dewey maintains throughout Logic: the Theory of Inquiry. Experimental investigation into subject-matters yield contents distinguished qualitatively from the contents of ordinary conscious perception (LW 12, 1938/1986 [8] (p. 459)). Dewey makes the Hegelian claim that a problem of knowledge arises when what is immediately observed ("a directly given sense-datum") is taken as identical to the object that constitutes an empirical, scientific conclusion (LW 12, 1938/1986 [8] (p. 460)) (Hegel makes the point that only through intelligence does an intuition accord with its representation, 
or rule. Sense-data, sense-qualia, perceptions and the like, are not identical to their representations (conceptual objects) absent the creative activity of intelligence. See [13] (pp. 379-382)). It then becomes the task to solve this discrepancy, leading to a theory of knowledge that runs together quality and concept. A holist theory in which the method of inquiry is primary does not generate this problem, for qualities are shown to be part of a continuum belonging to a further constituent (Dewey uses the example of light rays and the sun). Both the qualities (light rays) and the scientific object (sun) are part of "an extensive temporal-spatial continuum" (LW 12, 1938/1986 [8] (p. 461)).

This continuum is the focus of both this (Chapter 23) and the following chapter. In these, Dewey is keen to dissolve what he sees as the epistemological problem; the problem that occurs when qualities, sense-data, or perceptions are thought to be the same stuff as the scientific object.

The "problem" which occasions the epistemological interpretation arises when and because it is supposed that conceptions, in general and in particular, ought to be in some fashion descriptive of existential material. The idea that they should be descriptive is the only view possible when the strictly intermediate instrumental function, operatively realized, of conceptions is ignored (LW 12, 1938/1986 [8] (p. 461)).

The subject matters of scientific conceptions differ from the subject matters of existential material; the former is the result of experimental investigation into matters of existence (phenomena); the latter is felt; had, and undergone. This, Dewey is keen to claim, extends to propositions of universals and kinds; abstractions are not the same kind (Dewey calls them "logical forms") as existential or generic propositions of kinds. Dewey makes this explicit with regards to abstractions: for Dewey, abstractions are a different logical form than other propositions (existential propositions (LW 12, 1938/1986 [8] (p. 463)). The chemical conception of table salt is not identical with its ordinary, everyday understanding because their nexuses of relations differ. Moreover, it functions differently for different needs and ends. Strictly speaking, abstract conceptions operate only in the world of the scientists undertaking experimental investigation and using these as conceptual tools for further relating; they do not operate in the everyday world of immediate experiencing, even if these conceptions supply a richer and fuller set of relations and operations than ordinary conceptions.

Scientific method and subject-matter concerned Dewey at various stages of his philosophical development. They assumed an important topic in Democracy and Education. In Democracy and Education, Dewey's concern was experience and the role of both method and subject matter therein (MW 9, 1916/1980 [1] (p. 174)). As discussed, Dewey stressed experience as "a single continuous interaction of a great diversity (literally countless in number) of energies" (MW 9, 1916/1980 [1] (p. 174)). This Dewey calls a "double relation," and connotes logicality and rationality (MW 9, 1916/1980 [1] (p. 198)). Dewey offers the now-famous example of tap water vs. $\mathrm{H}_{2} \mathrm{O}$. The former has its purposes (drinking, washing, irrigating) which are different than the latter's (chemical uses). Neither indicates the truly objective relations holding amongst water and its uses, but the chemical conception of water relates more deeply than the ordinary understanding. The point is that in terms of relations, water and $\mathrm{H}_{2} \mathrm{O}$ are not the same. This is a claim Dewey makes in a regarding qualities perceived and scientific objects in Logic: the Theory of Inquiry.

\section{Continuity in the Logic: Social Inquiry}

The immediate focus for the chapters on Scientific Method and Scientific Subject Matter and Social Inquiry is the purported separation-even dualism—of the physical and social sciences. Characteristically, this dualism is for Dewey a disaster that needs immediate dissolution, chiefly through a demonstration of their (mutual) participation in a more general understanding of inquiry. (Dewey also distinguishes features of each and in so doing, stresses the conclusion that, though they participate in a general pattern of inquiry, the distinctions amongst their features necessitate treating them differentially.) In so doing, Dewey stresses the social context in which all physical inquiry participates. The intellectual and material cultures in which "physical inquiry" participates, shape that 
inquiry (LW 12, 1938/1986 [8] (p. 481)). The upshot of this (aside from the condemnation of strictly 'physicalist' approaches to science) is the oneness of inquiry with the social conditions in which it takes place. Indeed, this is the possibility for the self-correcting nature of inquiry-a characteristic Dewey says Charles S. Peirce first noted (LW 12, 1938/1986 [8] (p. 481)). It was Peirce, Dewey claimed, who first articulated the centrality of self-correction and the continuum in which inquiry resides. This concerns the long-run view of the legitimation of the results of scientific inquiry. For the results of inquiry only reveal their correctness, their "warrant", in an ever-expanding continuum of theoretical and practical consequences (LW 12, 1938/1986 [8] (p. 464)). Indeed, this is the solution to the otherwise intractable problem of how to bring form and subject matters together, in unity: unity only arises as a result of a continuum in which results of inquiries are established in a series or succession, and then 'tested' according to their theoretical and functional/practical consequences.

The upshot reveals another consequence: the claims of all inquiry (laws, theories, principles, tested hypotheses) are only authorized, only legitimated as to their social consequences, and these operate in an ever-widening social circle (LW 12, 1938/1986 [8] (p. 483)). Indeed, from the standpoint of inquiry, the agreement of the activities of inquiry with their social consequences "is the resolution of a problematic situation into a unified one" (LW 12, 1938/1986 [8] (p. 483)). This unified situation bespeaks the patterned, serial, continuous nature of inquiry in regards its social context: there is no separating out inquiry from its social context and consequences. Until scientific claims are 'tested' in the larger community of (scientific) inquirers, they are of a merely provisional—hypothetical—nature (LW 12, 1938/1986 [8] (p. 483)). Until there is agreement between the scientific claims made in an inquiry and the broader social consequences are ascertained (these are determined in part by the members of the larger community), inquiry remains incomplete and the resolution of the problematic situation (in this case, a social situation) remains unfulfilled.

The context for the agreement of social consequences with scientific inquiry in Dewey's chapter on Social Inquiry is first established in Democracy and Education. There, Dewey stresses the agreement between thinking and its social consequences: "Thinking, in other words, is the intentional endeavor to discover specific connections between something which we do and the consequences which result, so that the two become continuous" (MW 9, 1916/1980 [1] (p. 157)). The social consequences of thinking for the learner most intimately involve subject matter. Subject matter is the product of the (scientific) community: the authorized, legitimated results of previous inquiries. The unity of the learner with her subject matter is the educational equivalent of the unity of the scientific inquirer with her community of inquirers, and it is the latter that constitute the social consequences of all inquiries. The unity formed between the inquiry and its social consequences is a continuity: it is the enlargement of a series of habit-patterns. For that is what habit-patterns are: modifications of a human organism in regards its settling of a problematic or indeterminate situation, itself a result of transactions with the environment. Habit patterns are formed of the endings or closures of problematic events or situations in and through inquiries. Habit patterns are the form or shape of our learning. To learn, in other words, is to have inquired into, and resolved, a problematic, an unsettled, event or situation and to have modified, adapted, or adjusted oneself such that a new habit-pattern is formed. However, this habit pattern is itself a member of a series of habit-patterns: a continuous sequence of habit-patterns, temporally bound together.

The duality between the learner and her subject matter is thus the duality between scientific inquiry and its social consequences. In Democracy and Education, Dewey stresses the oneness of the learner with her subject matter; in Logic, Dewey stresses the oneness of the scientific inquiry with its social consequences. Of course, inquirers are learners, inasmuch as inquirers (and those they represent when they inquire) undergo modifications in their habit-patterns when an unsettled or problematic situation is resolved: inquirers, like learners, develop and grow. So Dewey's claims in Democracy and Education apply mutatis mutandis to his account of Social Inquiry in the Logic. However, what makes the account in Democracy and Education unique (and what makes it special for the Logic), is that for 
the first time, Dewey puts his claim for the unity of inquiry (and inquirer) with its (and her) social consequences in relief, in a practical setting.

\section{Conclusions}

There are (at least) two important claims Dewey makes in his Logic that are foreshadowed in Democracy and Education, and both concern the trait of continuity. The first concerns the serial nature of habit-patterns built up in the modification or adjustment of the human organism in inquiring or reflecting into unsettled or indeterminate situations, and the other concerns the unity of inquiry and its social consequences, foreshadowed in Democracy and Education by the unity of the learner and her subject matter. Doubtless, Dewey drew from a variety of sources in writing his monumental Logic: but these two claims in particular can be originally located in his treatise of the philosophy of education. This 'fact' makes it even more relevant for Dewey's philosophy as a whole.

Conflicts of Interest: The author declares no conflict of interest.

\section{References}

1. Dewey, J. Democracy and Education. In The Middle Works of John Dewey 1899-1924; Boydston, J.A., Ed.; Southern Illinois University Press: Carbondale, IL, USA, 1980; Volume 9 (1916).

2. Dewey, J. From Absolutism to Experimentalism. In The Later Works of John Dewey 1925-1952; Boydston, J.A., Ed.; Southern Illinois University Press: Carbondale, IL, USA, 1984; Volume 5 (1929-1930).

3. Dewey, J. Studies in Logical Theory. In The Middle Works of John Dewey 1899-1924; Boydston, J.A., Ed.; Southern Illinois University Press: Carbondale, IL, USA, 1976; Volume 2 (1902-1903), pp. 293-379.

4. Dewey, J. How We Think. In The Middle Works of John Dewey 1899-1924; Boydston, J.A., Ed.; Southern Illinois University Press: Carbondale, IL, USA, 1985; Volume 6 (1910-1911), pp. 177-356.

5. Dewey, J. Essays in Experimental Logic; Henry Holt \& Co.: New York, NY, USA, 1916.

6. Dewey, J. Logic of Judgments of Practice. In The Middle Works of John Dewey 1899-1924; Boydston, J.A., Ed.; Southern Illinois University Press: Carbondale, IL, USA, 1985; Volume 8 (1908), pp. 14-82.

7. Dewey, J. Essays on Philosophy and Education. In The Middle Works of John Dewey 1899-1924; Boydston, J.A., Ed.; Southern Illinois University Press: Carbondale, IL, USA, 1985; Volume 10 (1916-1917).

8. Dewey, J. Logic: The Theory of Inquiry. In The Later Works of John Dewey 1925-1952; Boydston, J.A., Ed.; Southern Illinois University Press: Carbondale, IL, USA, 1986; Volume 12 (1938).

9. Dewey, J. Experience and Nature. In The Later Works of John Dewey 1925-1952; Boydston, J.A., Ed.; Southern Illinois University Press: Carbondale, IL, USA, 1981; Volume 1 (1925).

10. Ratner, S.; Altman, J. John Dewey and Arthur Bentley: A Philosophical Correspondence 1932-1951; Rutgers University Press: New Brunswick, NJ, USA, 1964.

11. Dewey, J. School and Society. In The Middle Works of John Dewey 1899-1924; Boydston, J.A., Ed.; Southern Illinois University Press: Carbondale, IL, USA, 1976; Volume 1 (1899-1902), pp. 1-110.

12. Dalton, T. Becoming John Dewey: Dilemmas of a Philosopher and Naturalist; Indiana University Press: Bloomington, IN, USA, 2002.

13. Hegel, G.W.F. Encyclopedia of the Philosophical Sciences in Outline; Taubeneck, S., Translator; Continuum: New York, NY, USA, 1990.

(C) 2017 by the author. Licensee MDPI, Basel, Switzerland. This article is an open access article distributed under the terms and conditions of the Creative Commons Attribution (CC BY) license (http:/ / creativecommons.org/licenses/by/4.0/). 